\title{
Percutaneous endoscopic gastrostomy (PEG) using the modified introducer technique: clinical experience and description of an innovative new kit
}

\author{
Ezekiel Wong Toh Yoon* and Minoru Sakomoto \\ Department of Internal Medicine (Gastroenterology), Hiroshima Kyoritsu Hospital. Hiroshima City, Japan
}

For patients with impaired oral intake, percutaneous endoscopic gastrostomy (PEG) is an established safe and simple procedure to achieve long-term enteral tube feeding. This procedure originated with the pull technique [1] but today, there are four different techniques/ methods used to place a gastrostomy tube with the aid of endoscopy:

1. The pull technique

2. The push technique

3. The introducer technique

4. The modified introducer technique

The push technique [2], which was developed slightly later than the pull technique, is quite similar to the pull technique because the gastrostomy tube also passes through the oral cavity during insertion. Unlike the pull or push technique, the introducer technique [3] requires only a single insertion of the endoscope during procedure and the gastrostomy tube is inserted directly into the gastric lumen via the anterior abdominal wall using a trocar. However, due to the risk of mispuncture, the size of the trocar was limited (up to $15 \mathrm{Fr}$ size) and only enabled the insertion of small-caliber tubes. Today, newer kits with larger trocars using advance safety measures allow the placement of large-caliber tubes using this technique [4]. The modified introducer technique (also called the direct method) was developed in 2001 and made possible the placement of large-caliber gastrostomy tubes up to $24 \mathrm{Fr}$ size [5]. Like the introducer technique, the tubes are inserted directly via the abdomen without oral passage. However, instead of a large trocar puncturing into the stomach, a guidewire is first introduced into the gastric lumen through a small puncture needle (like the pull/ push technique). A large dilator is then inserted over the guidewire and after sufficient dilation of the puncture site, the dilator is removed and a gastrostomy tube is placed. In this article, we share our experience using a newly developed modified introducer technique kit (Figure 1, HALYARD Introducer Kit for Jejunal/Gastric Jejunal Feeding Tubes, Halyard Health, USA) on an 88-year-old woman with neurogenic dysphagia who was referred to our hospital for PEG.

Figure 2 presents a descriptive account using detailed endoscopic imaging of the procedure. After determining the intended puncture site on the anterior abdominal surface, the skin area was sterilized and local anesthesia applied. First, gastropexy was performed with the gastrointestinal anchor sets provided. A needle was punctured into the gastric lumen (Figure 2A), after which a T-fastener was pushed out from it (Figure $2 \mathrm{~B})$. After securing the $\mathrm{T}$-fastener, the needle was removed (Figures 2C and 2D). These steps were repeated three times in a triangular pattern surrounding the intended puncture site, leaving the $\mathrm{T}$-fasteners fixed against the gastric wall (Figure 2E). The T-fasteners were secured from the abdominal surface using absorbable sutures connected to low-profile external retention bumpers with locking bolsters (Figure 3, red arrow). Next, a small (roughly $1 \mathrm{~cm}$ ) incision was made on the intended puncture site and a guidewire was introduced into the gastric lumen through a small puncture needle (Figure 2F). After achieving a suitable orientation for the guidewire (Figure $2 \mathrm{G}$ ), the puncture needle was removed, leaving only the guidewire in place (Figure 2H). A telescoping 24Fr size dilator with a built-in peel-way external sheath was slowly introduced over the guidewire in a step by step telescoping manner (Figures 2I, 2J and 2K). After sufficient dilation, the dilator was removed and an over-the-wire stoma measuring device was inserted to estimate the appropriate length of the gastrostomy catheter to be placed (Figure 2L). It should be noted that this step is only necessary for placing button-type (skin level) gastrostomy catheters

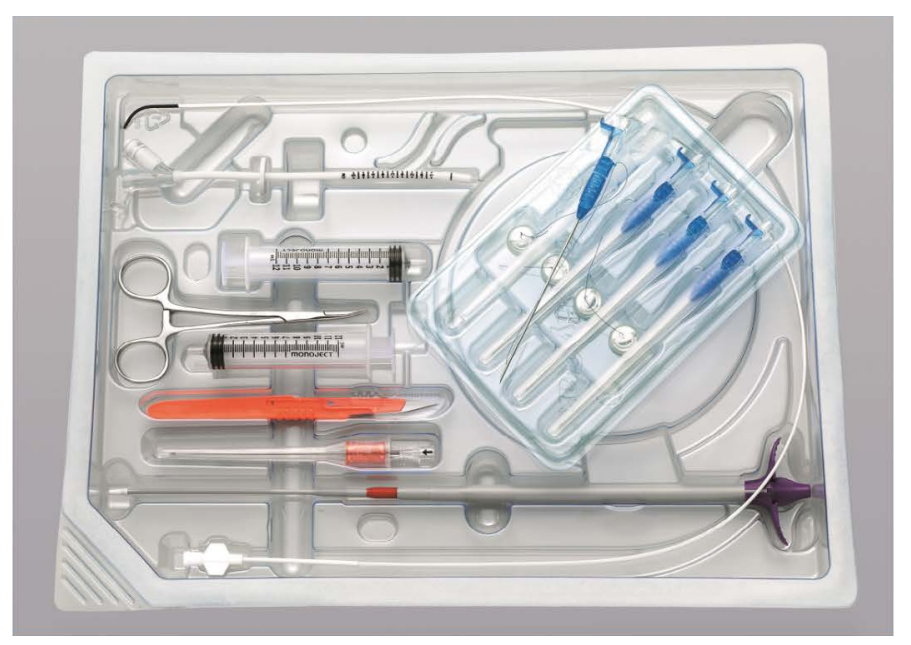

Figure 1. The modified introducer technique PEG kit described in this article (courtesy of Halyard Healthcare).

Correspondence to: Ezekiel Wong Toh Yoon, Department of Internal Medicine, Hiroshima Kyoritsu Hospital, 2-20-20 Nakasu Asaminami-ku Hiroshima City, Tel: 8182-879-1111. E-mail: easybs@hotmail.com

Key words: percutaneous endoscopic gastrostomy, modified introducer technique, enteral nutrition, tube feeding

Received: October 03, 2016; Accepted: October 18, 2016; Published: October 28, 2016 
Toh Yoon EW (2016) Percutaneous endoscopic gastrostomy (PEG) using the modified introducer technique: clinical experience and description of an innovative new kit

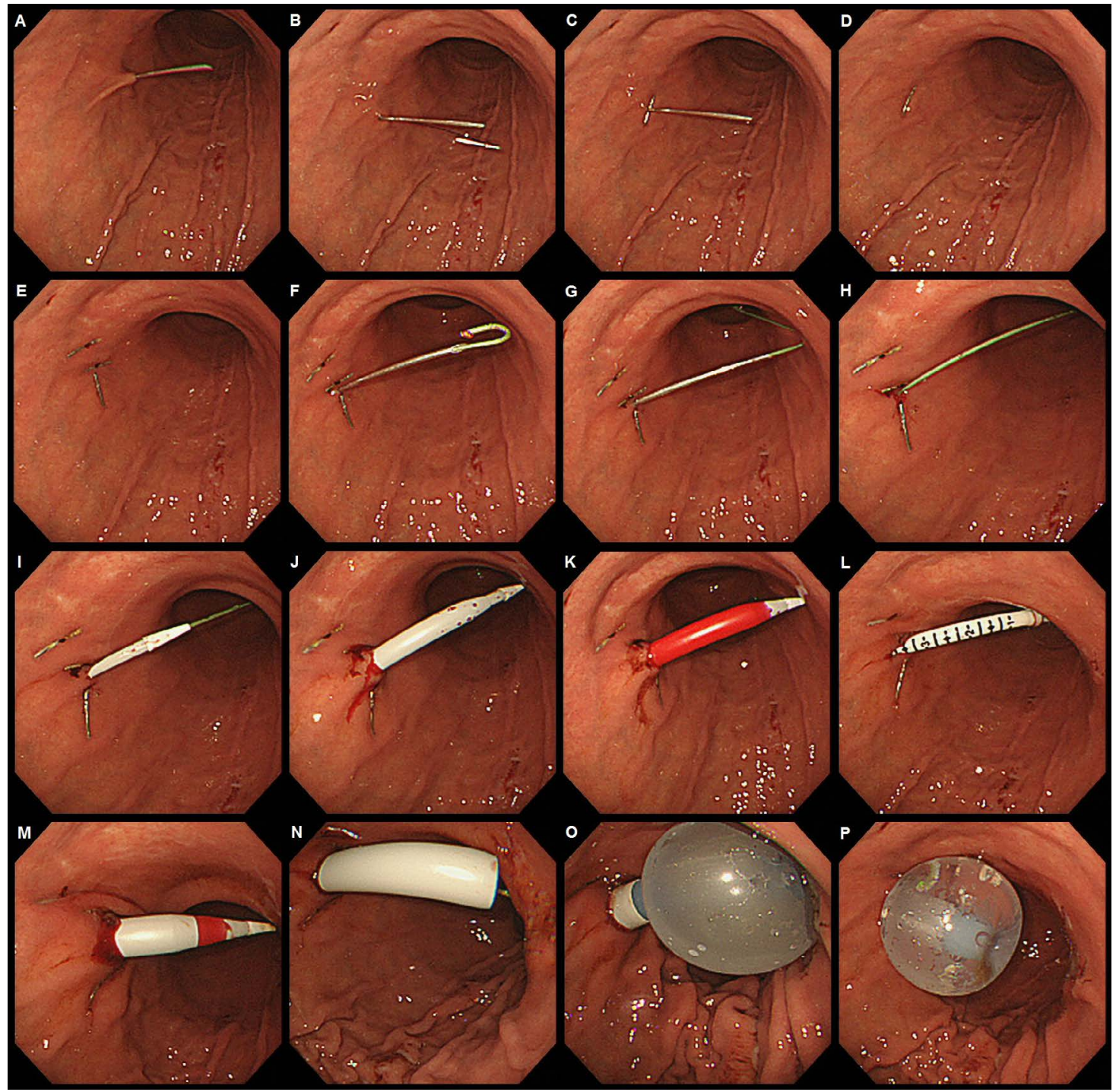

Figure 2. Endoscopic imaging of PEG procedure using the new modified introducer technique kit.

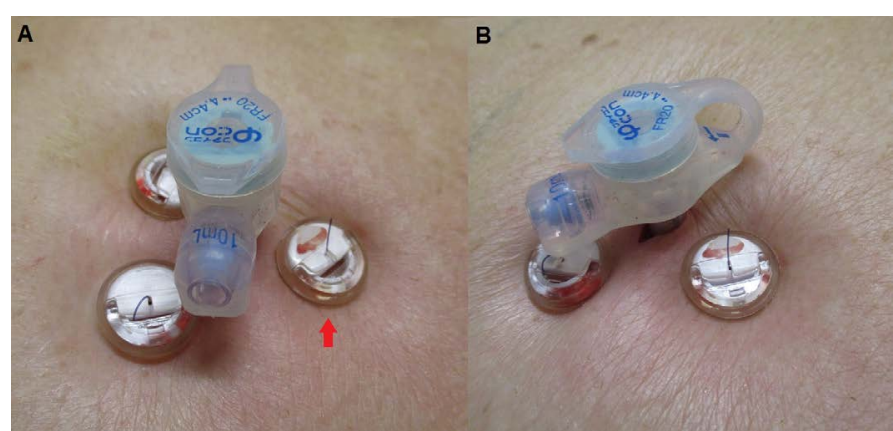

Figure 3. External view of the inserted gastrostomy catheter $(20 \mathrm{Fr}, 4.4 \mathrm{~cm}$ balloon button-type gastrostomy catheter) on the following day after PEG.

and that for tube-type catheters, the step described in Figure $2 \mathrm{~L}$ can be omitted. After measurement, the dilator was reinserted and full dilation performed until the peel-away external sheath was introduced into the gastric lumen (Figure 2M). Next, The dilator was removed, leaving only the external sheath with the guidewire in place (Figure $2 \mathrm{~N}$ ). A $20 \mathrm{Fr}$ size balloon button-type gastrostomy catheter with a shaft length of 4.4 $\mathrm{cm}$ was inserted into the external sheath over the guidewire. Then, the external sheath was slowly peeled away until the balloon tip could be inflated (Figure 2O). Finally, the external sheath was completely peeled off and the guidewire removed to leave only the gastrostomy tube in place (Figure 2P).

The external view of the gastrostomy tube on the following day is shown in Figure 3. The red arrow (Figure 3A) points to one of the three retention bumpers with the securing suture thread locked within the bolster. The gastrostomy puncture site is visible in Figure 3B. During gastropexy, it is important not to tighten the suture too much when securing it with the retention bumpers because mild (usually transient) inflammation and edema usually occurs by the following day. If the gastropexy is too tight, obstruction of blood flow may have a negative effect on wound healing. The sutures are absorbable and the retention bumpers usually falls of after a few weeks. The patient in this case was discharged on postoperative day 8 without any complications.

This newly developed modified introducer technique kit has been evaluated in animal models [6] but as far as we are aware of, the clinical use or description of this kit has yet to be reported. One of the characteristics of this kit is that it uses an external sheath just 

new kit

like the original introducer technique. The use of the telescoping dilator over the guidewire also enables intragastric maneuvering that makes it possible to place transgastric jejunal tubes under fluoroscopic guidance. This may be useful in patients with clinically demonstrated gastric feeding intolerance [7]. However, PEG procedure with this new kit is not without setbacks. Not only is the cost of this kit high, $\mathrm{T}$-fasteners have also been reported to migrate into the abdominal wall after procedure [8]. In addition, due to the many steps involved and described above, PEG using this kit may take a longer time to perform when compared to introducer technique kits, push/push technique kits or even other modified introducer technique kits. Nevertheless, due to the advantages offered by this kit, we recommend that it be used on a case by case basis, depending on the operator's expertise and experience.

\section{References}

1. Gauderer MW, Ponsky JL, Izant RJ Jr. (1980) Gastrostomy without laparotomy: a percutaneous endoscopic technique. J PediatrSurg15: 872-875.[Crossref]

2. Sacks BA, Vine HS, Palestrant AM, Ellison HP, Shropshire D, et al. (1983) A nonoperative technique for establishment of a gastrostomy in the dog. Invest Radiol18: 485-487.[Crossref]

3. Russell TR, Brotman M, Norris F (1984) Percutaneous gastrostomy. A new simplified and cost-effective technique. Am J Surg 148: 132-137.[Crossref]

4. Toh Yoon EW, Yoneda K, Nakamura S, Nishihara K (2016) Percutaneous endoscopic gastrostomy (PEG) using a novel large-caliber introducer technique kit: a retrospective analysis. EndoscInt Open. 4:E990-996. [Crossref]

5. Shigoka H, Maetani I, Tominaga K, Gon K, Saitou M, et al.(2012) Comparison of modified introducer method with pull method for percutaneous endoscopic gastrostomy: prospective randomized study. Dig Endosc. 24:426-431. [Crossref]

6. Maxwell CI, Hilden K, Glasgow RE, Ollerenshaw J, Carlisle JG, et al. (2011) Evaluation of gastropexy and stoma tract maturation using a novel introducer kit for percutaneous gastrostomy in a porcine model. JPEN J Parenter Enteral Nutr35: 630-635.[Crossref]

7. Toh Yoon EW, Yoneda K, Nakamura S, Nishihara K (2016) Percutaneous endoscopic transgastricjejunostomy (PEG-J): a retrospective analysis on its utility in maintaining enteral nutrition after unsuccessful gastric feeding. BMJ Open Gastroenterol. 3:e000098.

8. Sydnor RH, Schriber SM, Kim CY (2014) T-fastener migration after percutaneous gastropexy for transgastric enteral tube insertion. Gut Liver 8: 495-499.[Crossref]

Copyright: $\mathbb{C} 2016$ Toh Yoon EW. This is an open-access article distributed under the terms of the Creative Commons Attribution License, which permits unrestricted use, distribution, and reproduction in any medium, provided the original author and source are credited. 